\title{
Production of (E) 10-Hydroxy-8-octadecenoic Acid with Lyophilized Microbial Cells
}

\author{
A. Bódalo, J. Bastida, M.F. Máximo, A.M. Hidalgo and M.D. Murcia \\ Department of Chemical Engineering, University of Murcia, 30071, Murcia, Spain
}

\begin{abstract}
Lyophilized non-proliferating microbial cells of Pseudomonas sp. 42A2 showed their ability to catalyze the bioconversion of oleic acid into (E)-10-hydroxy-8-octadecenoic acid (MHOD) and (E)7,10-dihydroxy-8-octadecenoic acid (DHOD). The reaction conditions were optimized in order to produce the maximum amount of MHOD. At $30^{\circ} \mathrm{C}$ and using phosphate buffer $(0.1 \mathrm{M}$ and $\mathrm{pH}=8)$, an initial substrate concentration of $10 \mathrm{mg} \mathrm{mL}^{-1}$ and a cell concentration of $8 \mathrm{mg} \mathrm{mL}^{-1}$, practically all the oleic acid in the medium was biotransformed within $42 \mathrm{~h}$, with hardly any DHOD produced $\left(1.4 \mathrm{mg} \mathrm{mL}^{-1}\right)$.
\end{abstract}

Key words: Hydroxy Fatty Acids, Pseudomonas sp., Biotransformation, Oleic Acid

\section{INTRODUCTION}

Hydroxy Fatty Acids (HFA) are multifunctional molecules that have a variety of applications. For example, HFA and their derivatives are used in cosmetics, paints and coatings, lubricants and in the food industry. They are useful chemical intermediates in the synthesis of fine chemicals and pharmaceuticals. Moreover, some of them may protect plants against microbial infection, although the mechanism of these antimicrobial effects is poorly understood [1].

HFA are derived from a variety of natural sources, including plant seed oils, glycosides, microorganisms, epicuticular waxes of coniferous trees, plant cutin, tall oil and cork [2]. At present, castor oil (ricinoleic acid) and its derivatives are the major commercial source of hydroxy fatty acids. However, the fluctuating supplies and prices of castor oil have led users to seek alternative raw materials.

Since Wallen [3] reported in 1962 the first bioconversion of oleic acid to 10-hydroxystearic acid using pseudomonas, the microbial conversion of unsaturated fatty acids has been widely exploited to produce new, value-added hydroxy fatty acids. As an example, three different unsaturated monohydroxy derivatives of oleic acid (11-hydroxy-9-octadecenoic, 10-hydroxy-8-octadecenoic and 9-hydroxy-10octadecenoic acids) are produced when Pseudomonas sp. $32 \mathrm{~T} 3$ grows in a mineral medium with oleic acid as the main carbon substrate [4].

It has been reported that the microbial oxidation of oleic acid with Pseudomonas sp. 42A2 (NCIMB 40044) yields (E)-10-hydroxy-8-octadecenoic acid (MHOD) and (E)-7,10-dihydroxy-8-octadecenoic acid (DHOD) [5-8]. This activity has also been found in other Pseudomonas strains [9-12]. The high oxygen levels demanded for its biotransformation due to the incorporation of molecular oxygen into the oleic acid
[6] led the authors to study a new production strategy consisting of an immobilized system with nonproliferating cells. The conversion reached in a batch reactor operating with fresh non-proliferating cells was $64 \%$, which could be increased to $91 \%$ by using the immobilized cell system [8].

Among the above mentioned compounds, the monohydroxyl derivative of oleic acid seems to have several potential applications in the food industry (due to its similarity with ricinoleic acid) and much effort has gone into finding methods for its high yield production. In order to produce pure MHOD, several alternatives have been explored. First of all, periplasmatic lipoxygenase has been extracted and used to catalyze the oleic acid bioconversion to MHOD [13]. However, this is probably the most expensive choice because the enzyme cannot be reused and the continuous production of MHOD is not possible. Immobilization of the enzyme might be a good alternative, but has not yet been explored. Another alternative might be to use nonproliferating whole cells as catalyst, in which case the reaction conditions should be such as to avoid as far as possible the transformation of MHOD to DHOD. In the present study lyophilized microbial cells are used as an alternative since these are more attractive from an industrial point of view, being cheaper than the immobilized derivatives and easier to store and transport than the fresh cells. No previous articles have been reported on this system using lyophilized cells. The bioconversion is carried out with non-proliferating cells and the optimal conditions of the reaction are stated in order to maximize the production of MHOD.

\section{MATERIALS AND METHODS}

Organism and Chemicals: Pseudomonas sp. 42A2 NCIMB 40045 was a kind gift from Dr. Manresa, (Laboratory of Microbiology, Faculty of Pharmacy, 
University of Barcelona, Spain). The cells were lyophilized with skimmed milk (Cryodos, Telstar, Barcelona, Spain). Oleic acid Riedel-de Haën ${ }^{\circledR}$ (minimum 58\%) was purchased from Sigma Chemical Co. To prepare standard solutions, oleic acid (approx. 99\%) was acquired from Sigma Chemical Co.; pure MHOD and DHOD were kindly provided by Dr. Manresa.

Reactor Experiments: Unless otherwise stated, bioconversion was carried out at $150 \mathrm{rpm}$ and $30^{\circ} \mathrm{C}$ in a $500 \mathrm{ml}$ baffled Erlenmeyer flask, in which $0.8 \mathrm{~g}$ of lyophilized cells were added to $100 \mathrm{ml}$ of oleic acid suspension $\left(10 \mathrm{mg} \mathrm{mL}^{-1}\right)$ in the appropriate buffer. Samples were taken every $7 \mathrm{~h}$ and oleic acid, MHOD and DHOD concentrations were determined by HPLC.

Fatty acids Analysis: Samples were centrifuged at $10000 \times \mathrm{g}$ for $20 \mathrm{~min}$. The supernatant was acidified with $1 \mathrm{~N} \mathrm{HCl}$ to $\mathrm{pH}=2$ and extracted three times with equal volumes of chloroform. The organic phases were collected and dried with anhydrous $\mathrm{Na}_{2} \mathrm{SO}_{4}$. The solvent was removed by rotary evaporation and fatty acids were dissolved in absolute ethanol.

A $10 \mu \mathrm{l}$ aliquot was injected into a Nova-Pack $\mathrm{C}_{18}$ (4 $\mu \mathrm{m}$ particle size) reverse-phase column. Samples were eluted with acetonitrile/ $30 \mathrm{mM}$ phosphoric acid (80:20 $\mathrm{v} / \mathrm{v})$ at $30^{\circ} \mathrm{C}$, at a flow rate of $1.5 \mathrm{~mL} \mathrm{~min}^{-1}$ and detected by their absorbance at $205 \mathrm{~nm}$. Area values were converted to concentrations using a calibration curve (oleic acid $\left(\mathrm{mg} \mathrm{mL}^{-1}\right)=0.41 \times$ area $\times$ $10^{-6}$; MHOD $\quad\left(\mathrm{mg} \mathrm{mL}^{-1}\right)=1.41 \times$ area $\times 10^{-6}$; DHOD $\left(\mathrm{mg} \mathrm{mL}^{-1}\right)=2.28 \times$ area $\left.\times 10^{-6}\right)$.

\section{RESULTS AND DISCUSSION}

First, the suitability of lyophilized cells of Pseudomonas sp. 42A2 to produce MHOD from oleic acid was checked. The reaction conditions were similar to those used in a previous work with lipoxygenase extracted from the microbial periplasm [13]. As shown in Fig. 1, lyophilized non-proliferating microbial cells were able to catalyze the bioconversion of oleic acid into MHOD, the maximum production being reached at $35 \mathrm{~h}$. Moreover, the oxygen concentration level was not a key parameter in the biochemical reaction in these conditions (open vessel) because similar results were obtained when air was bubbled into the reaction medium (data not shown). Figure 1 also shows that a significant concentration of DHOD could be measured in the reaction medium after $14 \mathrm{~h}$ although it continued to be accumulated as time progressed. After $35 \mathrm{~h}$ of reaction, the slope representing DHOD production increased sharply, this increase being matched by a concomitant decrease in MHOD concentration. This sudden change has been observed previously [7] and has been attributed to the enzymatic transformation of MHOD into DHOD. If the biochemical reaction is

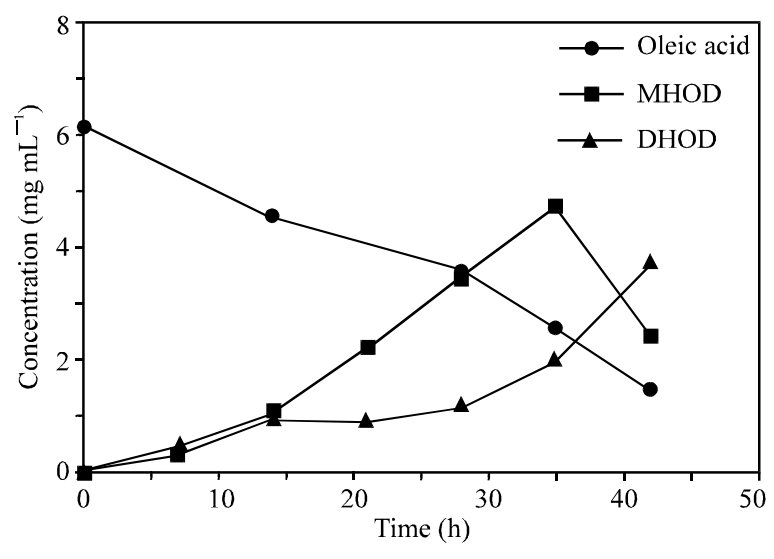

Fig. 1: Time Course of the Species Concentration Reactor Conditions:

Substrate concentration $=10 \mathrm{mg} \mathrm{mL}^{-1}$ of commercial oleic acid Biocatalyst concentration $=8 \mathrm{mg} \mathrm{mL}^{-1}$ of lyophilized cells Temperature $=30^{\circ} \mathrm{C} \cdot \mathrm{pH}=7$

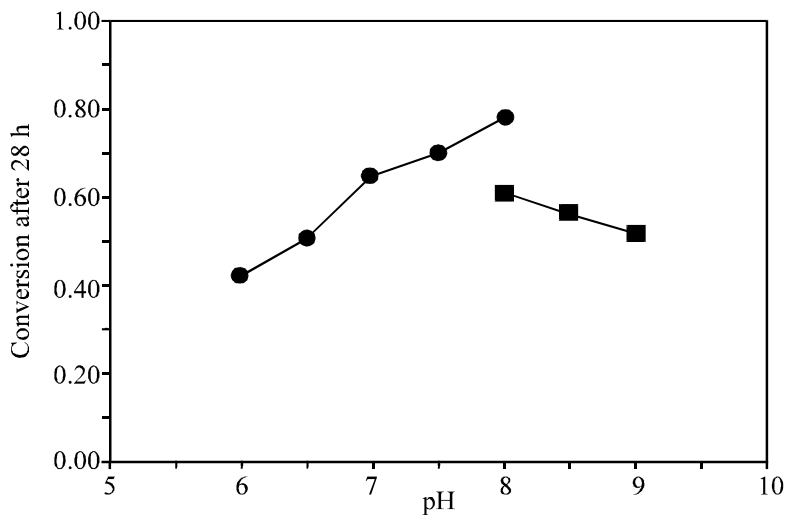

Fig. 2: Optimum pH. (•) Phosphate Buffer 0.05 M. (匹) Borate Buffer $0.05 \mathrm{M}$

Experimental Conditions:

Substrate concentration $=5 \mathrm{mg} \mathrm{mL}^{-1}$ of commercial oleic acid Biocatalyst concentration $=8 \mathrm{mg} \mathrm{mL}^{-1}$ of lyophilized cells Temperature $=30^{\circ} \mathrm{C}$

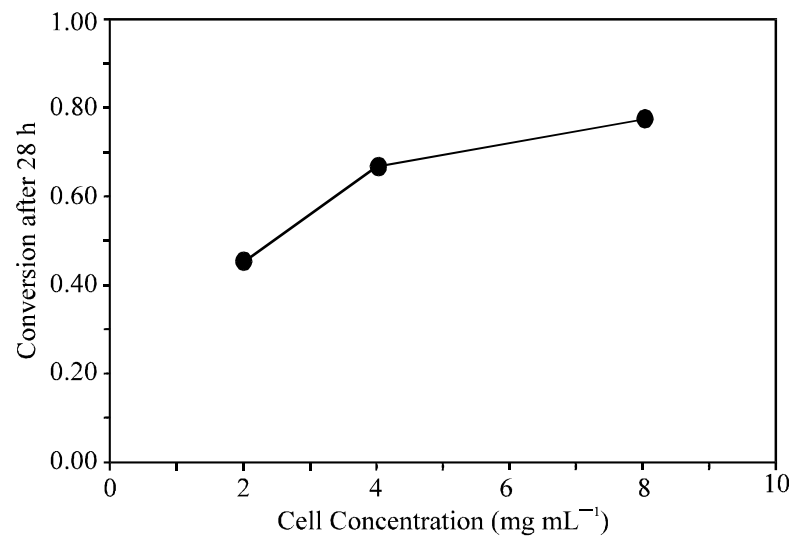

Fig. 3: Conversion after 28 $\mathrm{h}$ for Different Cell Concentrations

Experimental Conditions:

Substrate concentration $=5 \mathrm{mg} \mathrm{mL}^{-1}$ of commercial oleic acid Temperature $=30^{\circ} \mathrm{C} \cdot \mathrm{pH}=8$ 


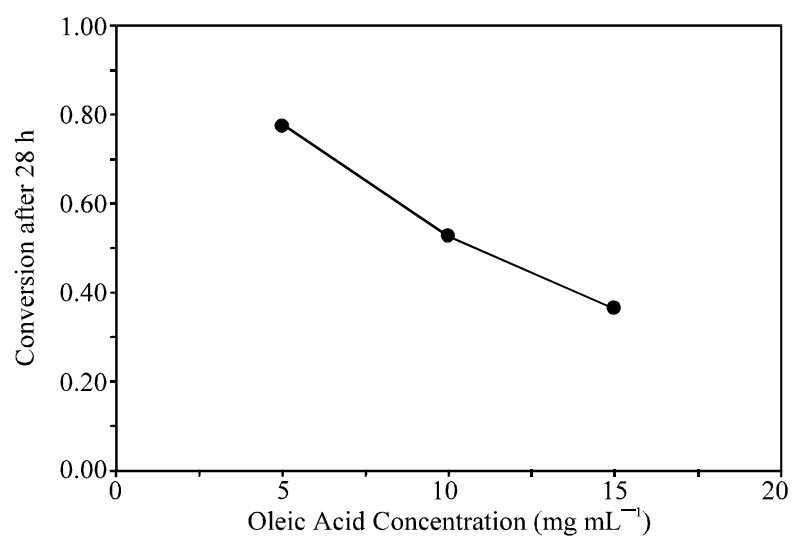

Fig. 4: Conversion after $28 \mathrm{~h}$ for Different Substrate Concentrations

Experimental Conditions:

Biocatalyst concentration $=8 \mathrm{mg} \mathrm{mL}^{-1}$ of lyophilized cells Temperature $=30^{\circ} \mathrm{C} \cdot \mathrm{pH}=8$

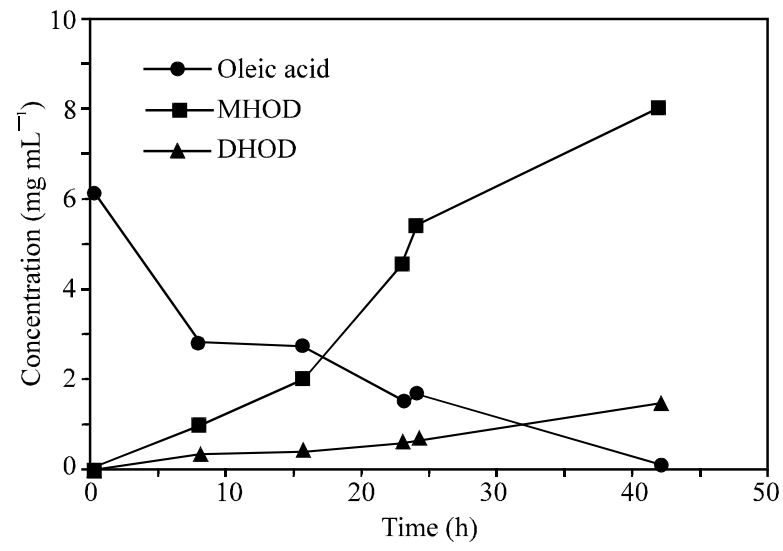

Fig. 5: Time Evolution of the Species Concentration after Optimizing the Reaction

Experimental Conditions:

Substrate concentration $=10 \mathrm{mg} \mathrm{mL}^{-1}$ of commercial oleic acid Biocatalyst concentration $=8 \mathrm{mg} \mathrm{mL}^{-1}$ of lyophilized cells Temperature $=30^{\circ} \mathrm{C} \cdot \mathrm{pH}=8$

allowed to proceed, the effect of water evaporation becomes significant and the mass balance is no longer fulfilled.

In order to maximize MHOD production several experiments were carried out varying temperature, $\mathrm{pH}$ and cell and substrate concentrations. The reactions were stopped after $28 \mathrm{~h}$ because, at this time, DHOD production and evaporation are still negligible. Conversion, defined as the ratio between the oleic acid concentration achieved and the initial concentration, was used to compare the experimental results.

Temperature did not seem to have strong influence on the rate of oleic reaction, since in the experiments carried out at 30,40 and $50^{\circ} \mathrm{C}$, the conversion values after $28 \mathrm{~h}$ were $0.77,0.67$ and 0.65 , respectively. As biotransformation at $30^{\circ} \mathrm{C}$ showed a slightly higher conversion value after $28 \mathrm{~h}$, this temperature was used in subsequent experiments.
The effect of $\mathrm{pH}$ on the biocatalytic activity was determined using two buffer solutions: $0.05 \mathrm{M}$ phosphate buffer ( $\mathrm{pH}$ 6-8) and $0.05 \mathrm{M}$ borate buffer (pH 8-9). First, $\mathrm{pH}$ regions close to neutrality were explored by using phosphate buffer. The results are shown in Fig. 2, where conversion values after $28 \mathrm{~h}$ are represented against $\mathrm{pH}$. As no optimum value was reached, borate buffer was prepared to check more alkaline regions. In the literature phosphate buffer $0.1 \mathrm{M}(\mathrm{pH}$ 7.2) is considered as optimal for the biotransformation of oleic acid into MHOD and DHOD when the reaction is catalyzed by recently harvested cells, although higher $\mathrm{pH}$ values have not been examined. In our case, for lyophilized cells, $0.05 \mathrm{M}$ phosphate buffer $\mathrm{pH}=8.0$ was considered as optimal, which is similar to that reported in a previous study [13] where borate buffer $0.2 \mathrm{M}(\mathrm{pH}=8.5-9)$ was described as optimum when periplasmatic lipoxygenase was used as catalyst.

Experiments were conducted at different cell concentrations. Figure 3 shows that there was a notable improvement in conversion after $28 \mathrm{~h}$ when cell concentration increased from 2 to $4 \mathrm{mg} \mathrm{mL}^{-1}$, although there was not such a sharp increase when the cell concentration was raised to $8 \mathrm{mg} \mathrm{mL}^{-1}$. However, the enhanced conversion by more then ten units (from 0.67 to 0.78 ) justified using the highest cell concentration in subsequent experiments.

To complete the optimization, several oleic acid concentrations were checked. The results are shown in Fig. 4. The lineal decrease in the represented variable with increasing substrate concentration indicates the convenience of working at low values even though low productivities are achieved. As a consequence a compromise of $10 \mathrm{mg} \mathrm{mL}^{-1}$ was considered adequate to achieve sufficient conversion and productivity.

To conclude this study, the reaction course in the established optimum conditions is shown in Fig. 5, in which the concentration of the three main species (oleic acid, MHOD and DHOD) is plotted against time. The complete disappearance of oleic acid after $42 \mathrm{~h}$ together with the limited production of DHOD $\left(1.4 \mathrm{mg} \mathrm{mL}^{-1}\right)$ results in the production of MHOD with a high degree of purity. On the other hand water evaporation means that a material balance is not fulfilled after the biotransformation process, when theoretically about $6.1 \mathrm{mg} \mathrm{mL}^{-1}$ of MHOD plus DHOD should be present. Moreover, it is important to notice that, after the optimization process, the reaction conditions are not noticeably different from those used in the preliminary experiment (Fig. 1), the only difference being the $\mathrm{pH}$ value. However, it can be observed that $\mathrm{pH}$ has a strong influence on the production of the undesired hydroxy fatty acid DHOD. It seems that the enzymatic activity responsible for the biotransformation of MHOD into DHOD is not favored by an alkaline $\mathrm{pH}$, thus allowing the accumulation of the monohydroxyl octadecenoic acid. 


\section{CONCLUSION}

The production of (E)-10-hydroxy-8-octadecenoic acid, using lyophilized non-proliferating microbial cells of Pseudomonas sp. 42A2, is presented as an alternative to obtain a new hydroxy fatty acid. The procedure does not require external oxygen supply. Alkaline conditions allow us to transform the oleic acid into MHOD without noticeable DHOD production. The use of lyophilized cells could be an attractive start point for a future industrial application because they are easier of handle than fresh cells and cheaper than immobilized derivatives.

\section{AKNOWLEDGEMENT}

This work was partially supported by PPQ2000-0105P4-03 from the CICYT.

\section{REFERENCES}

1. Suzuki, Y., O. Kurita, Y. Kono, H. Hyakutake and A. Sakurai, 2005. Structure of a new antifungal $\mathrm{C}_{11}$-hydroxy fatty acid isolated from leaves of wild rice (Oryza officinalis). Biosci. Biotechnol. Biochem., 59: 2049-2051.

2. Hayes, D.G., 1996. Catalytic activity of lipases toward hydroxy fatty acids. A review. J. Am. Oil Chem. Soc., 73: 543-549.

3. Wallen, L.L., R.W. Jackson and R.G. Benedict, 1962. Microbial production of 10-hydroxyestearic acid from oleic acid. Arch. Biochem. Biophys., 99: 249-253.

4. Rodríguez, E., M.J. Espuny, A. Manresa and A. Guerrero, 2001. Identification of (E)-11-hydroxy9-octadecenoic acid and (E)-9-hydroxy-10octadecenoic acid by biotransformation of oleic acid by Pseudomonas sp. 32T3. J. Am. Oil Chem. Soc., 78: 593-597.

5. de Andrés, C., E. Mercadé, J. Guinea and A. Manresa, 1994. (E)-7,10-dihydroxy-8-octadecenoic acid produced by Pseudomonas sp. 42A2: Evaluation of different cultural parameters of the fermentation. World J. Microbiol. Biotechnol., 10: 106-109.
6. Guerrero, A., I. Casals, I. Busquets, Y. León and A. Manresa, 1997. Oxydation of oleic acid to (E)10-hydroperoxy-8-octadecenoic and (E)-10hydroxy-8-octadecenoic acids by Pseudomonas sp. 42A2. Biochim. Biophys. Acta, 1347: 75-81.

7. Bastida, J., C. de Andrés, J. Culleré, M. Busquets and A. Manresa, 1999. Biotransformation of oleic acid into 10-hydroxy-8E-octadecenoic Acid by Pseudomonas sp. 42A2. Biotechnol. Lett., 21: 1031-1035.

8. Culleré, J., O. Durany, M. Busquets and A. Manresa, 2001. Biotransformation of oleic acid into (E)-10-hydroxy-8-octadecenoic Acid and (E)7,10-8-octadecenoic acid by Pseudomonas sp. 42A 2 in an immobilized system. Biotechnol. Lett., 23: $215-219$.

9. Hou, C.T. and M.O. Bagby, 1991. Production of a new compound, 7,10-dihydroxy-8-(E)octadecenoic acid from oleic acid by Pseudomonas sp. PR3. J. Ind. Microbiol., 7: 123-130.

10. Hou, C.T. and M.O. Bagby, 1992. 10-Hydroxy-8(Z)-octadecenoic acid, an intermediate in the formation of 7,10-dihydroxy-8-(E)-octadecenoic acid from oleic acid by Pseudomonas sp. PR3. J. Ind. Microbiol., 9: 103-107.

11. Kim, H., H.W. Gardner and C.T. Hou, 2000. 10(S)Hydroxy-8(E)-octadecenoic acid, an intermediate in the conversion of oleic acid to 7,10-dihydroxy8-(E)-octadecenoic acid. J. Am. Oil Chem. Soc., 77: 95-99.

12. Kuo, T.M., K.J. Ray and L.K. Manthey, 2003. A facile reactor process for producing 7,10dihydroxy-8(E)-octadecenoic acid from oleic acid conversion by Pseudomonas aeruginosa. Biotechnol. Lett., 25: 29-33.

13. Busquets, M., V. Deroncele, J. Vidal-Mas, E. Rodríguez, A. Guerrero and A. Manresa, 2004. Isolation and characterization of a lipoxygenase from Pseudomonas 42A2 responsible for the biotransformation of oleic acid into (S)-(E)-10hydroxy-8-octadecenoic acid. Anton Leeuw. Int. J. G., 85: 129-139. 